\title{
Analysis of land suitability for small earth dams Using Multi Criteria Evaluation (MCE) in the Geographic Information System (GIS)
}

\author{
Arezoo Safavian ${ }^{1}$, Mohamad Amani ${ }^{2}$ \\ ${ }^{1}$ M.Sc. student, Department of Environmental Management, Faculty of Environmental, \\ Gorgan University of Agricultural Sciences and Natural Resources, Gorgan, Iran. \\ ${ }^{2}$ M.Sc. student, Department of Watershed Management, Faculty of Watershed, Gorgan University \\ of Agricultural Sciences and Natural Resources, Gorgan, Iran. \\ E-mail address: fariad.sincere@gmail.com, safavian_az@yahoo.com
}

Keywords: proportionality earth, small earthen dams, GIS, Weighted linear combination

\begin{abstract}
In many parts of the world, especially in arid and semi-arid, one of the solutions to deal with the major flood season comes, is the dam, as well as water storage dams to store flood also reduced the flood peak flow and damages resulting from it. It must be built in places that best performance in terms of the volume of the reservoir and reduce their discharge. In this paper, using a combination of linear and GIS environment, the proportion of land for the construction of small earth dams in the watershed Kal Ajy in the East province with an area of $170.90 \mathrm{~km}$, based on five criteria (slope of the stream bed, the distance from the village, away from sources of credit, apart from agricultural lands, areas with severe erosion) to assess and map the proportion of the land in the study area was prepared. This map priority areas for the construction of small dams and earthen offers. The results indicate that 27 percent of the region is important for small earth dams are suitable.
\end{abstract}

\section{INTRODUCTION}

Spatial analysis and geographic often have multivariate and multi criteria. Geographers, planners and decision-makers spatial (location) to solve their issues faced with a range of data and information that, due to the volume and nature of the integration and analysis of different, often very complex and difficult in some Despite good rainfall Average Golestan province, yet in some areas, especially eastern problem is dehydration. Kaul Ajay watershed is located in the eastern part of Golestan province that despite the many seasonal rivers, the people of the region with drinking water shortages for agricultural purposes as well as their health and are exposed during low rainfall. The small earthen dams and water storage is the way to deal with possible flooding. In this paper, two options weighted linear combination of GIS and we aim to achieve is the location for the dam (2). Geographic information systems, with numerous features and capabilities for collecting, storing, editing, data analysis and modeling, so a useful tool for spatial planners in the evaluation of a number of criteria are considered. Basically, the ultimate goal of providing GIS is support for planning and decision making (Nazri, 2006: 9-10). There are several ways to analyze and evaluate a measure of the proportion of land that is the most common method of weighted linear combination (1).

In this article it has been tried based on five criteria and using weighted linear combination, the proportion of land for the construction of small earth dams in the watershed Kaul Ajay, a GIS environment to be evaluated(3). The method For this reason selected The first is simple And one of the most common methods of multi-criteria evaluation, Secondly easily run in Geographical Information Systems Third, analysts can view information on the importance of benchmarks and review them to best apply (6). In the field of multi-criteria decision-making methods_Solving problems in decision-making, numerous studies have been done in the world and Iran which some of them are mentioned below: (14). 
Tal Svoray and colleagues in a study on the integration of GIS and multi-criteria evaluation methods to assess ecological areas on land for four possible: Protection of natural forest areas, residential areas and industrial areas were used. The method proposed in this study, One layer for each of the four public events and a final layer Which can be the best use for each piece of land is proposed provides. The results of the model used in this study (Figure 1) (5).
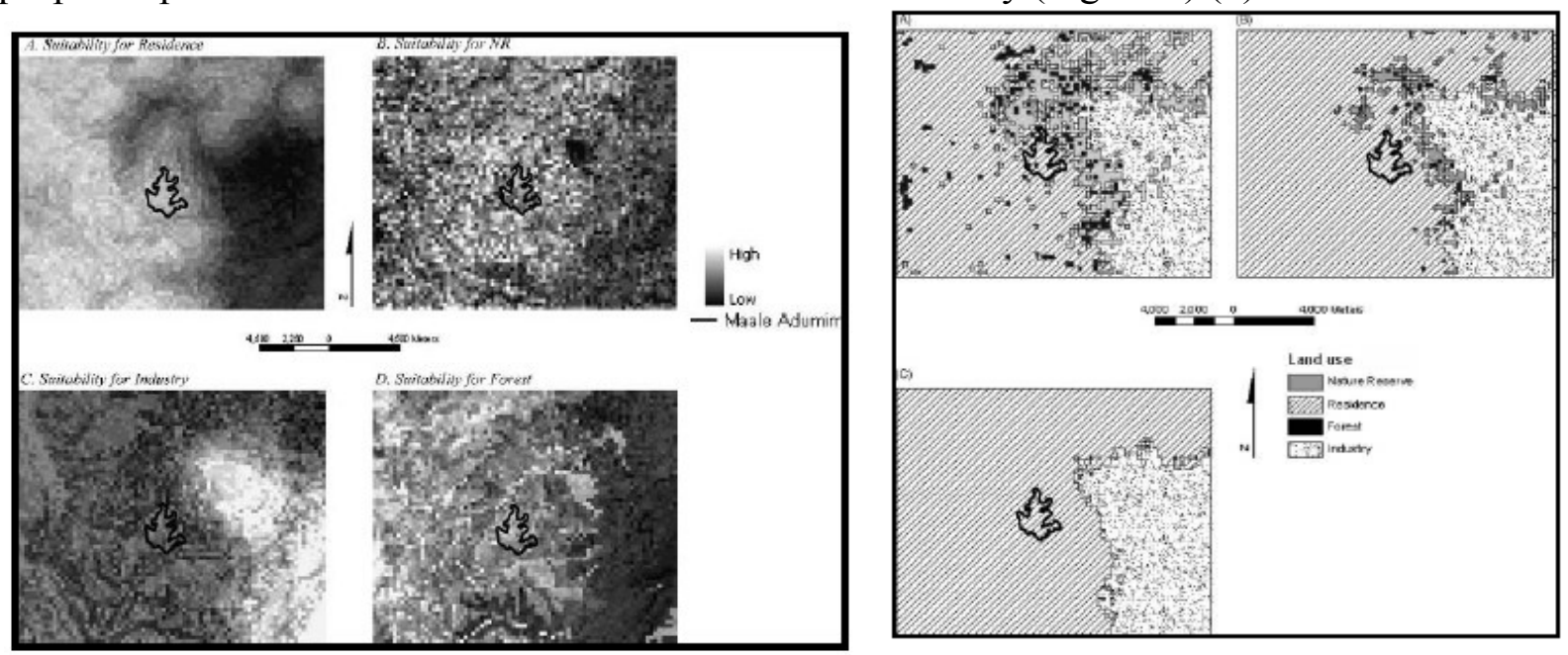

Figure 1 -Result of research (Svoray et al, 2005)

In a study by Ron Store and Jyrki Kangas GIS data and spatial analysis, combined with modern techniques to improve the assessment decision on the habitats used in large areas. In this study, GIS as a platform to manage, combine and display data standards and data in order to produce new tools (especially by spatial analysis functions) was used. In this research, standardization, weighting and combining multiple criteria evaluation criteria by MCE)) was carried out. In the end, the proposed method has been implemented on a case study and the results (Figure 2), respectively (4).

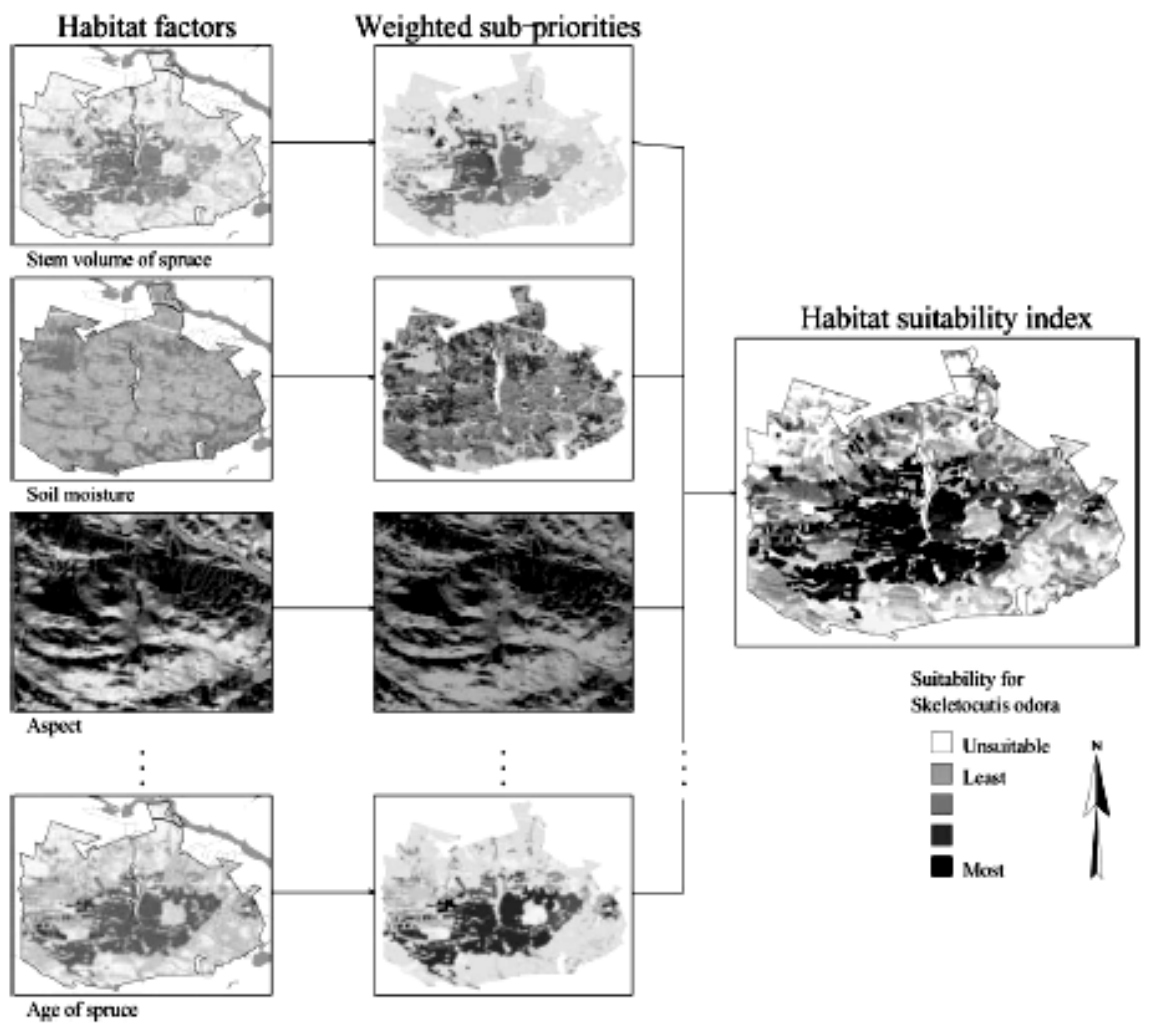

Figure 2. The results of the study (kangas. Store, 2001)

Cary Higgs in his research on the advantages of using multi-criteria evaluation integrated with GIS to enhance public participation in the debate stems(12). He is to demonstrate the benefits, 
challenges and opportunities that decision-makers in terms of increasing public participation in the process of waste management face saied And finally We concluded that the use of multi-criteria evaluation based on GIS can increase the efficiency of public participation in the plan have Bsyarbalayy (8). Habibi and others in research, using a combination of multiple criteria evaluation model and GIS to locate landfill proposed municipal solid waste. In this study, using data such as the distance from the city, away from roads, airports, land use, land capability and so on through the integration of models and maps based on fuzzy logic, the best place for the disposal of municipal solid waste the study sample (Figure 3) was selected (7).

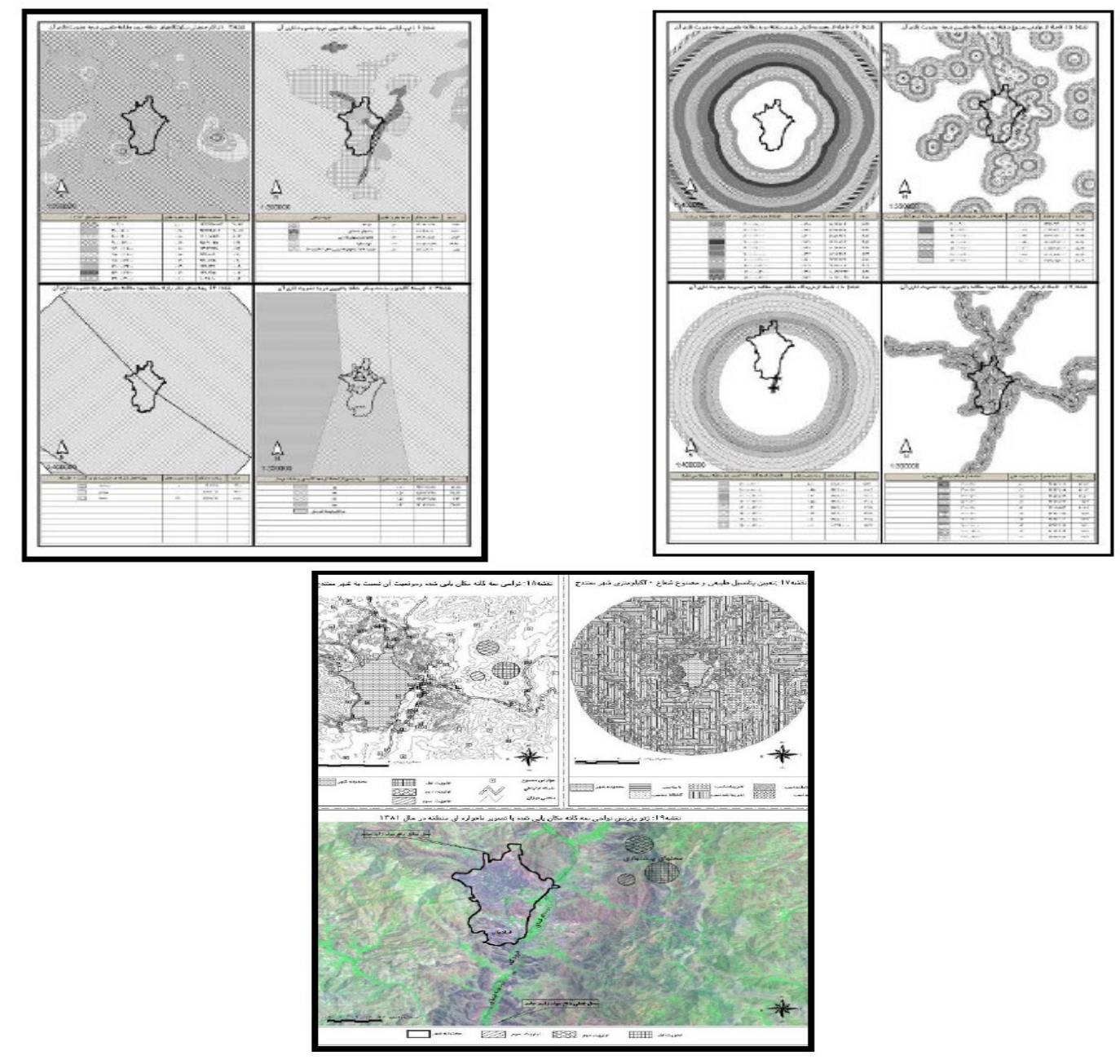

Figure 3. The results of the study (Habibi et al., 1384)

\subsection{Introducing the study area}

Kal Ajy basin with an area of 17099.93 hectares In the area east $55^{\circ} 18^{\prime} 04^{\prime \prime}$ to $55^{\circ} 29$ ' $32^{\prime \prime}$ And latitude $37^{\circ} 35^{\prime} 44^{\prime \prime}$ to $37^{\circ} 45^{\prime} 37^{\prime \prime}$ Almost in the north of Kalale city, is located in the East province. Villages in this area, including Akhjy, gachy sow and Kochak Gogche is that Located in the north of the basin, The villages surrounding this area Can be Named sojy and yoli badrag (10). (Figure 4). This area is located in the country and province show. 


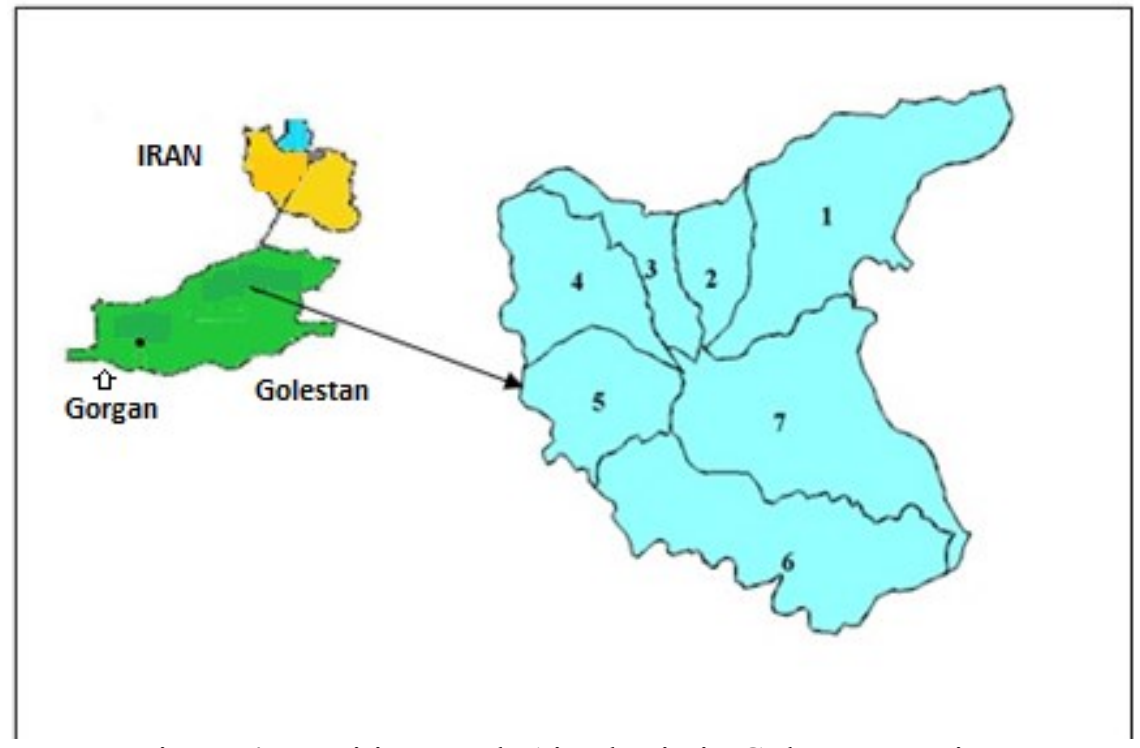

Figure 4 - Position Kaul Ajay basin in Golestan province

Kal Ajy basin was divided into seven sub-basins and sub-basins hydrological conditions 1 to 6, and No. 7 in the basin is the area that can be seen in Figure 5(13).

\section{MATERIALS AND METHODS}

In this paper, effective measures earthen dam at the location where they will be discussed in more detail below were prepared in the GIS environment.

\subsection{Slope of Stream bed}

Framework for dam embankment slope gradient of less than $5 \%$, because the slope is inversely related to the size of the tank. Figure 5 shows the map of the region and set the drainage channels with a slope of less than $5 \%$ of the show (11).

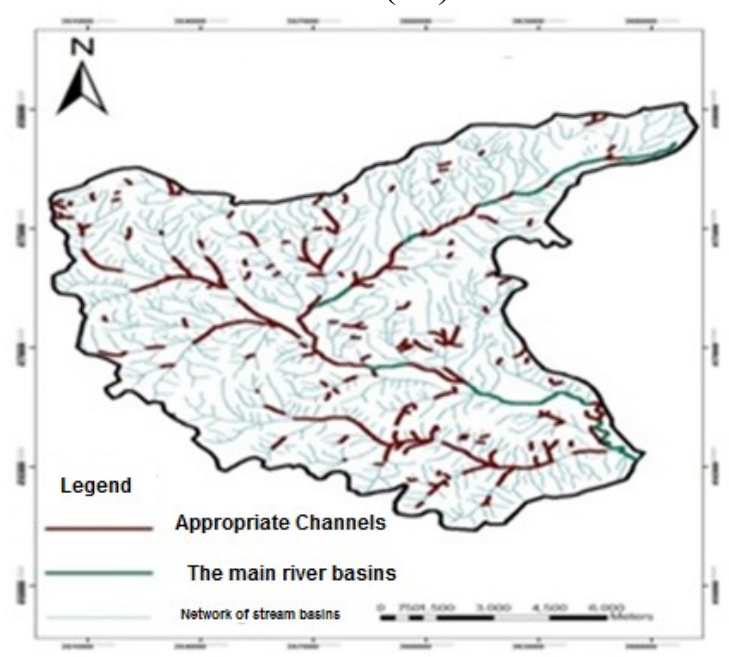

Figure 5 - A map of the area and determine drainage channels with a slope of less than 5\%

\subsection{The distance from village}

Near the dam site and the village can be used as an indicator easy to find skilled manpower for the construction of the dam is raised. The dam was built close to residential areas and rural areas, access to and transfer of stored water is easier and less costly. Figure 6 shows the location of villages and Privacy intervals (16). 


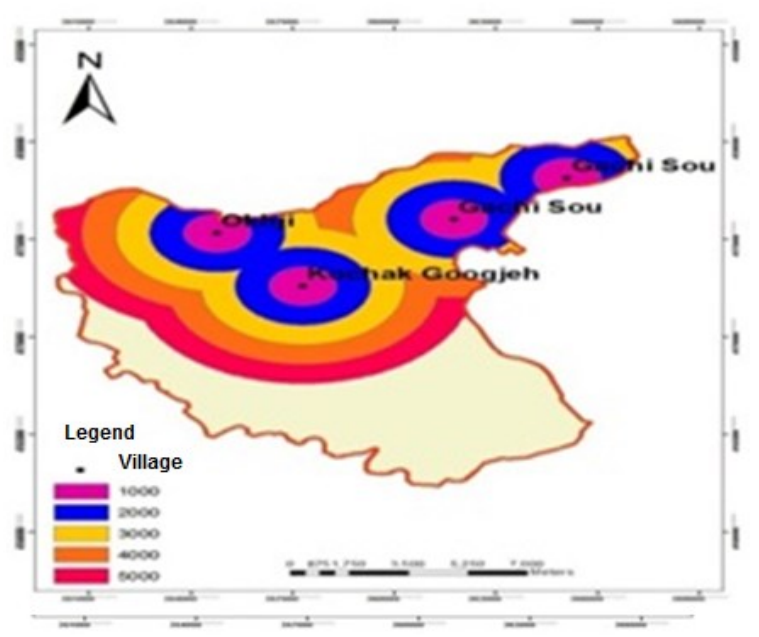

Figure 6 - The villages in the area and to determine the boundaries of the villages

\subsection{Areas with severe erosion}

It covers areas gully erosion and alluvial terraces of the old and make Palyvsvl that Production of sediment and erosion can be a problem for dam construction and fill the reservoir from sediments as well as a platform for the structures are weak and permeable, so in other areas, the figures are wrong. In Figure 7, these areas can be seen and considered optional (15).

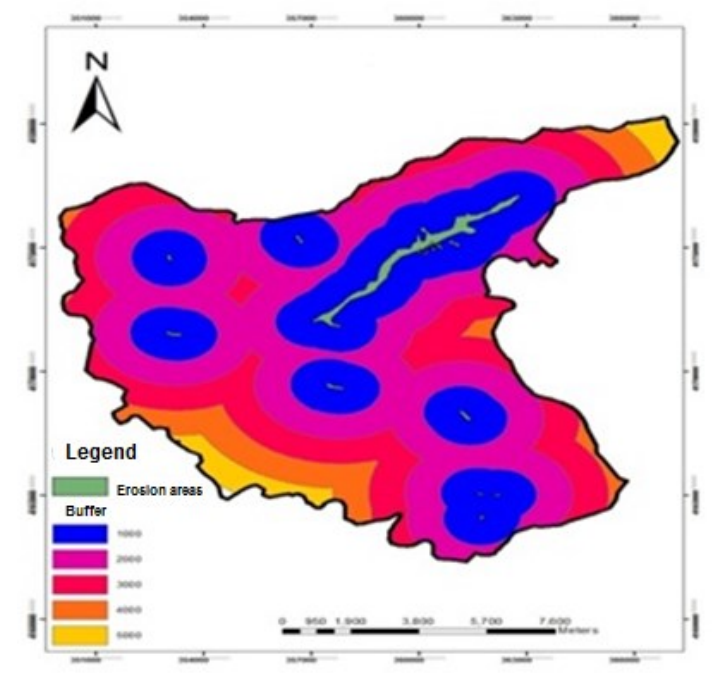

Figure 7- Map of attrition and space created for this region

\subsection{Distance from Borrow}

Clay sources of research carried out in the past that were identified by spectral analysis were extracted and the distance to the radius of $5 \mathrm{~km}$ from the dam were considered as optional. In Figure 8 , and access resources within the limits of the resources shown. 


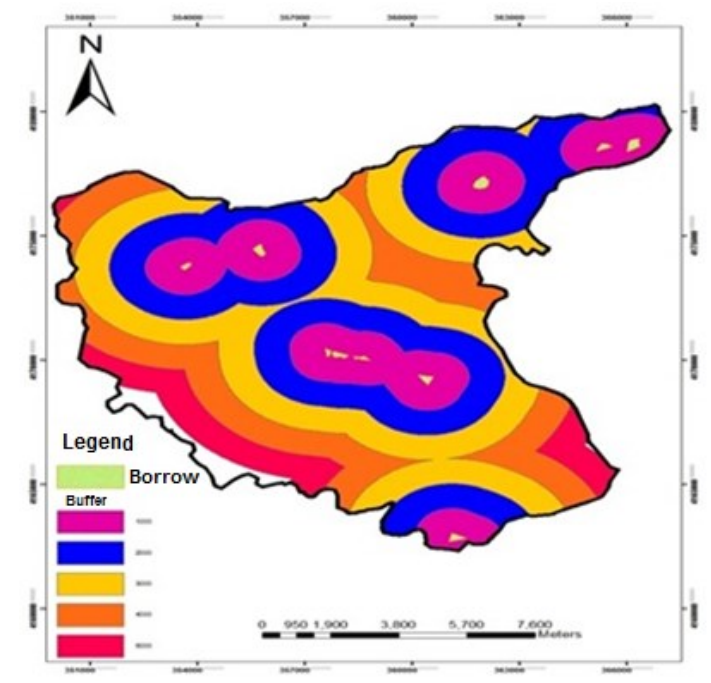

Figure 8. Show location Borrow And to determine the boundaries of the resource

\subsection{The distance from Agriculture land}

Areas intended for the construction of the dam should be close to agricultural lands up to Water is readily available to farmers and ranchers affected and the cost of transferring water from the reservoir to agricultural land and reduce intubation in these areas. Figure 9 (9).

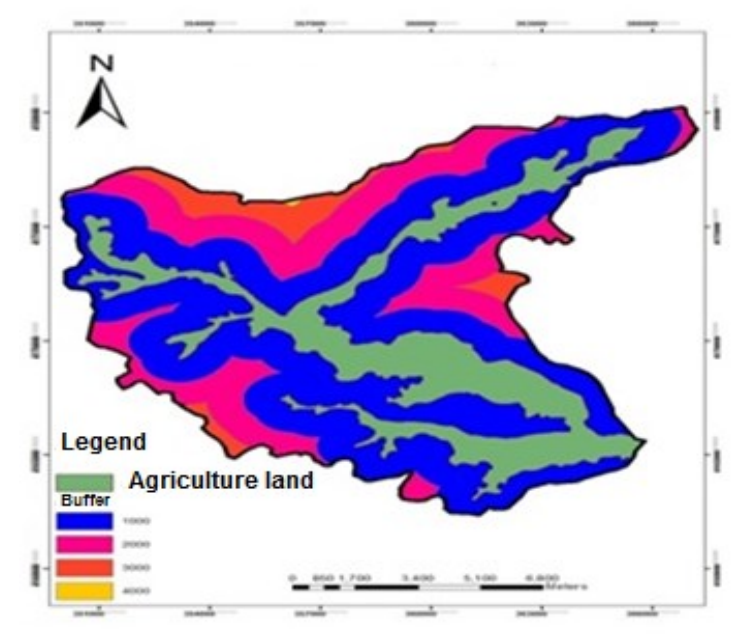

Figure 9. Map of agricultural land and agricultural land to determine space

For spatial analysis and multi-criteria evaluation software was used Idrisi and raster format. For this purpose, the layers were collected in Idrisi and for all maps UTM coordinate system is considered the same and the size of each picture element (pixel) in the maps of $30 * 30 \mathrm{~m}$ (14). Criteria and variables considered for analysis in this study include 5 standard is the fit. For standardization and unification of the value scale map layers of fuzzy and weighting criteria weighting method analytic hierarchy process (AHP) was used (15). In the final analysis, multicriteria evaluation (to match the ground) technique Vzn $\neg$ Dar linear combination (WLC) was used. The overall process integration model of multi-criteria decision making (MCDM) and GIS to solve problems is in Figure 10. 


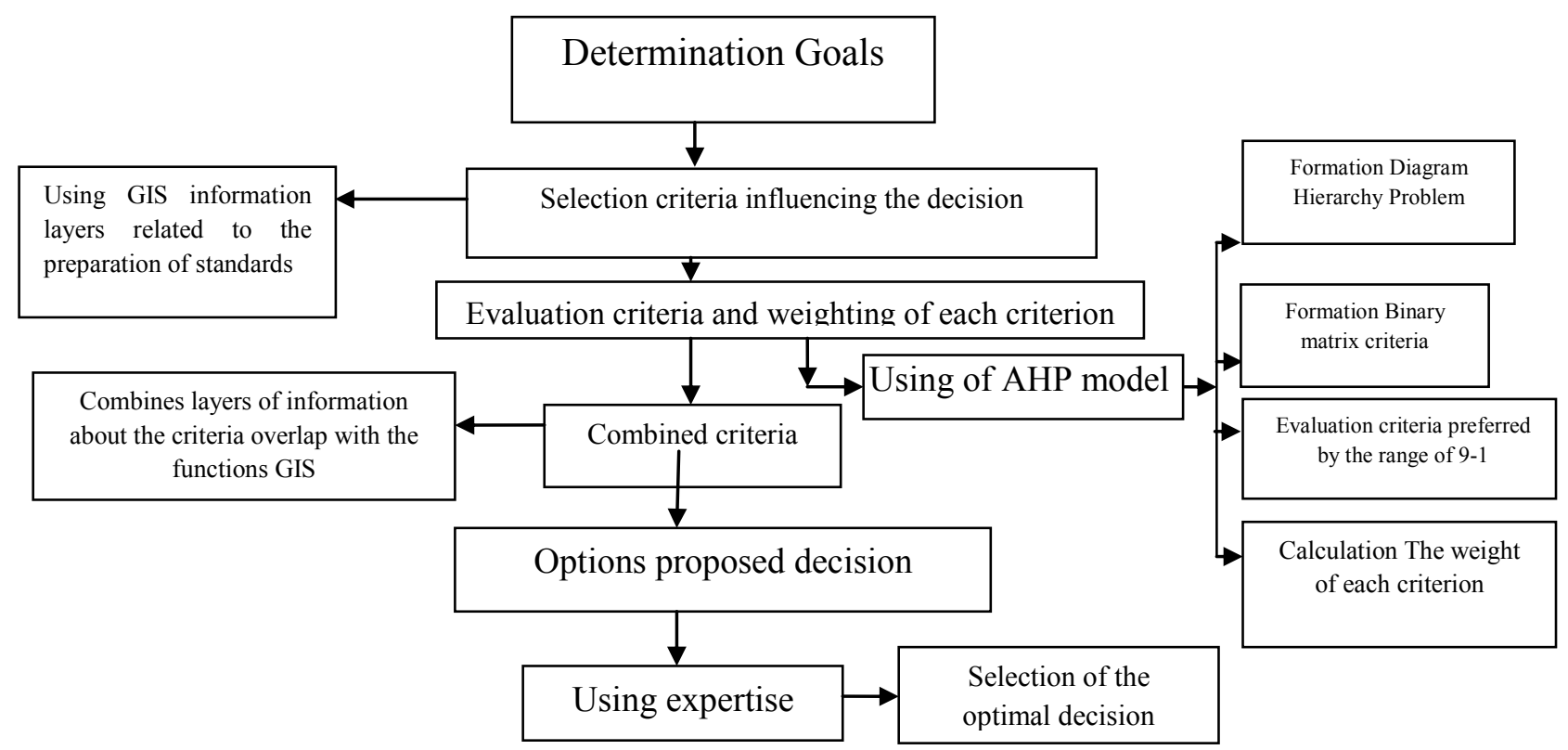

Figure 10 - The general process model integration of Multi-Criteria Decision Making (MCDM) and GIS to solve problems

\section{RESULTS}

The results of this study are as follows:

$>$ Multi-criteria decision-making strategies in combination with GIS can be a useful framework to solve complex problems of decision-making (especially spatial decisions) provide.

Using multi-criteria decision-making based on GIS is so simple and flexible that any number of criteria can be used to solve a problem. Although it should be noted that with the increasing number of criteria, decision makers may face difficulties in giving weight to these criteria.

$>$ The multi-criteria decision-making process based on GIS, in steps of evaluation criteria, can be given in terms of different groups interested in the issue of the role and functions of each area of use. This process can lead to increased public participation in municipal decisionmaking. Future research in this area could test the efficiency of this method.

The diversity and complexity of the subject information and spatial analysis has led to the GIS is widely used in solving problems. Multi-criteria evaluation method for comparing the relative importance of various characteristics together and integrating data according to their importance in the decision (16). In this paper, the evaluation criteria and weight scales comparable standard method of analytical hierarchy process (AHP) was determined as follows.

The distance from the village (0.26), distance to Borrow (0.23), tilt Bstrabrahh of (0.13), areas with severe erosion (0.312), and distances of agricultural land (0.068).

Run the MCE method in GIS environment, including the following (11):

1. Defined set of evaluation criteria (map layers)

2. Standardization and turn the scale values And a map layer values

3. Determining criteria weights

4. Multiplying the standard weight corresponding map layers

5. Production The final map with operations overlay

In Figure 11, the final map from the weighted linear combination is shown. 


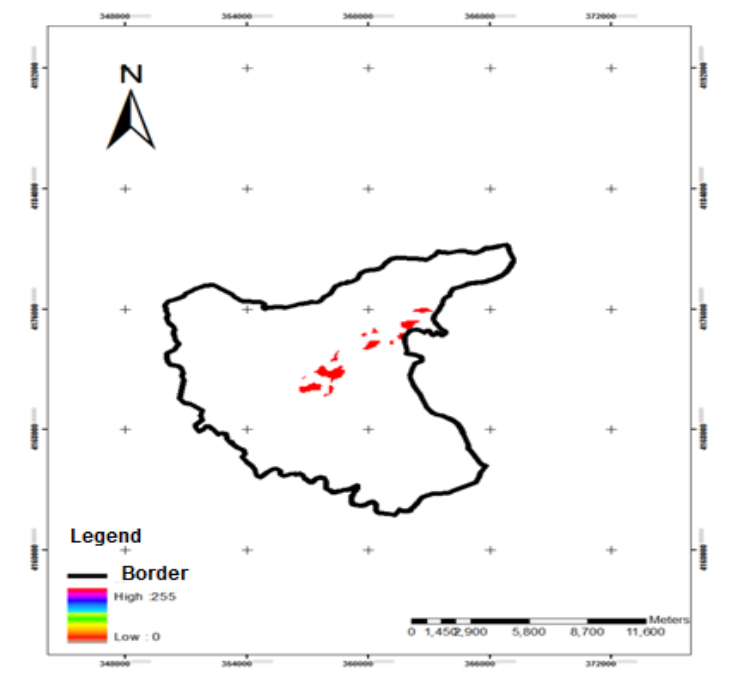

Figure 11 - Map suitability of land for the construction of dams in the watershed Kal Ajy

\section{CONCLUSION}

Map of the evaluation of several criteria to determine the suitability of the land in the watershed Kal Ajy (with the aim of locating suitable areas for small-earth dam), map compilation raster format values are those values between zero and one. Higher values (to one) in the map indicates suitability for the construction of a dam and lower (zero indicates the proportion of land is less important. The map shows the location of red earth dams that $27 \%$ of the total area included. As the results show, GIS capability in the field of collecting, editing, modifying and analyzing massive amounts of data and information, spatial and non-spatial, the tool Support for spatial analysis and planning (3). Functions of basic and advanced the implementation of a wide range of statistical and mathematical operations on data and spatial algorithms makes it possible. The operation largely limitations and complications of the large volume of information, the nature of the measures to reduce discrepancies caused by variation analysis to reduce computation time. (Carver, 1992: 105-127)

While relatively good accuracy as well. In connection with the analysis of physical fitness of land for development, in addition to procedures Multi Criteria Evaluation (MCE), can be fuzzy methods and methods based on Boolean logic was also helped, while the number of evaluation criteria to match the features and This increased restrictions.

\section{References}

[1] Ahmad Nazri Muhamad Ludin, Ahris Yaakup, Siti Zalina Abu Bakar, Anuar Maidin, Lily Hammadah Ramle.,(2006). GIS And Planning Support System For Klang Valley Region, Malaysia . In: ASIA GIS 2006, international conference, March 9-10, 2006, Johor ,Malaysia.

[2] Burrough, P.A. (1990) "Methods of spatial analysis in GIS". International journal of geographic information system, 4, pp. 221-223.

[3] Carver, S. \& Openshaw, S. (1992) A Geographic Information Systems approach to locating nuclear waste disposal sites. In: Clark, M., Smith, D. \& Blowers, A. (eds): Waste Location: Spatial Aspects of Waste Management, Hazards and Disposal, pp. 105-127. Routledge, London.

[4] Chrisman, N. (2002) "Exploring geographic information system". John Wiley and sons. New York, pp. 143-151.

[5] Deren Li, Mingjun Peng, Zhenfeng Shao.,(2006), Design and Implementation of Urban Management and Service Grid Based on Spatial Database, In: ASIA GIS 2006, international conference, March 9-10, 2006, Johor ,Malaysia. 
[6] Eastman, J.R., Kyem, A.K., Toledano, J., 1993. A procedure for multi-objective decision making in GIS under conditions of conflicting objectives. In: Proceedings of the Fourth European Conference on Geographic Information Systems, 29 March-1 April 1993, Genoa, Italy.

[7] Gary Higgs., (2006), integrating multi-criteria techniques with geographical information

[8] Systems in waste facility location to enhance public participation, Journal of Waste Management \& Research, volume24, pp 105-117.

[9] Giovanni, F. Marco Gardenti, Francesca Caparrini , Fabio Castelli .2008. A methodology for the pre-selection of suitable sites for surface and underground small dams in arid areas: A case study in the region of Kidal, Mali. Physics and Chemistry of the Earth 74-85. pp.

[10] IDRISI for windows software (version 2.008) (1998). Help Menu. Program Modules. Decision support section. Clark University.

[11] Malczewski, J., 1999. GIS and Multicriteria Decision Analysis. John Wiley and Sons, New York.

[12] Mui-How Phua, Mitsuhiro Minowa.,(2005), A GIS-based multi-criteria decision making approach to forest conservation planning at a landscape scale: a case study in the Kinabalu Area, Sabah, Malaysia, Journal of Landscape and Urban Planning, volume 71, pp 207-222.

[13] 12-Padmavathy, A.S.Ganesha, Raj, K.Yogarajan, N.,Thangavel, p.\& Chandrasekhar, M.G 2002. Check Dam Site Selection Using GIS Approach. National Natural Resources Management System, ISRO Headquarters, New BEL Road, AntarikshBhavan,Bangalore-560 094,India. 123_127. pp.

[14] Ron Store and Jyrki Kangas., (2001). Integrating spatial Multi-criteria evaluation and expert knowledge for GIS-based habitat suitability modelling, Journal of Landscape and Urban Planning, volume 55, pp 79-93.

[15] Tal Svoray, Pua Bar (Kutiel), Tsafra Bannet.,(2005). Urban land-use allocation in a Mediterranean ecotone: Habitat Heterogeneity Model incorporated in a GIS using a multicriteria mechanism, Journal of Landscape and Urban Planning, volume 72, pp 337-351.

[16] Tim, S.2010.Manual Small Earth Dams (A guide to siting, design and construction).124 pp.

[17] Singh, J.P. darshdeep Singh,P.K.litoria,2009. Selection of Suitable Site for water harvesting Structures in Soankhad Watershed, Punjab using Remote Sensing and Geographical Information System (RS\&GIS) Approach-A Case Study.Indian.21-35.pp. 